\title{
Structural and parametric synthesis of a document management system
}

\author{
D.G. Zybin ${ }^{1}$, A.V. Kalach ${ }^{1, *}$, A.A. Rogonova ${ }^{2}$, A.I. Bashkatov ${ }^{2}$, \\ M.A. Klementeva ${ }^{2}$ \\ ${ }^{1}$ Voronezh Institute of the Federal Penitentiary Service of Russia, 1a, Irkutskaya Str., \\ Voronezh, Russia \\ ${ }^{2}$ FGBNU "Expert and Analytical Center", 33, Talalikhina Str., Building 4, Moscow, Russia \\ *E-mail: zdg77@mail.ru
}

\begin{abstract}
The structures representing the document flow processes in an organization are considered by synthesizing them from the simplest structures. Presented in the form of graphs the processes of movement of documents become formalized and unambiguously defined. Using classification of typical structures of information flows and available mathematical model of management system, it is possible to formalize processes of movement of documents and their interaction in the form of management model, and also to make technical specification for development of information system and finished formalized statement of the problem of structure-parametric synthesis
\end{abstract}

Keywords: electronic document management, structural-parametric synthesis, control algorithm 


\title{
Структурно-параметрический синтез системы управления документопотоком
}

\author{
Д.Г. Зыбин ${ }^{1}$, А.В. Калач ${ }^{1, *}$, А.А. Рогонова ${ }^{2}$, А.И. Башкатов ${ }^{2}$, \\ М.А. Клементьева ${ }^{2}$ \\ ${ }^{1}$ Воронежский институт ФСИН России, 1, а, ул. Иркутская г. Воронеж, Россия \\ ${ }^{2}$ ФГБНУ «Экспертно-аналитический центр», 33/4, ул. Талалихина, г. Москва, Россия \\ *E-mail: zdg77@mail.ru
}

\begin{abstract}
Аннотация. Структуры, представляющие процессы документооборота в организации, рассматриваются путем их синтеза из простейших структур. Процессы перемещения документов, представленные в виде графиков, становятся формализованными и однозначно определенными. Используя классификацию типовых структур информационных потоков и имеющуюся математическую модель системы управления, можно формализовать процессы движения документов и их взаимодействия в виде модели управления, а также составить техническое задание на разработку информационной системы и законченную формализованную постановку задачи структурнопараметрического синтеза.
\end{abstract}

Ключевые слова: электронный документооборот, структурно-параметрический синтез, алгоритм управления

\section{1. Введение}

Документы, сопровождающие деятельность учреждения, могут создаваться в разных информационных системах, т. е. происходит дублирование информации в прикладных системах и системе документооборота. С другой стороны, необходимо обеспечить интеграцию этих систем в общую систему документооборота. Кроме того, следует учитывать следующие факторы [1]:

- обособленность данных по пониманиям информационной безопасности;

- невозможность полностью исключить бумажный документооборот;

- наличие определенных объектов рабочего процесса, которые требуют определенного способа их автоматизации [2-7].

Еще одной проблемой проектирования системы документооборота организации является изменчивость структуры его документооборота: под влиянием различных внешних и внутренних влияний (приказов и директив вышестоящих министерств, ведомств, органов государственной власти и других организаций, новых федеральных образовательных стандартов, государственных стандартов и т.д.), структура организации оптимизируется и, 
следовательно, созданная система управления документооборотом должна обладать структурной и функциональной гибкостью [8-11]. Решением этой проблемы станет использование структурно-параметрического синтеза, благодаря которому можно оптимизировать систему электронного документооборота (СЭД) не только по ряду показателей, но и изменять структуру ее модулей и отдельных частей в зависимости от поставленных задач.

\section{2. Алгоритм системы управления документопотоком}

Для создания алгоритма структурно-параметрического синтеза СЭД применим функциональные диаграммы в нотации IDEF0 [12, 13].

Это дозволит детально отобразить процессы, происходящие в предметной области, а также, наглядно представит входную и выходную информацию, используемые управляющие действия и механизмы (инструменты), и, кроме того, графический язык IDEF0 прост, лаконичен и является стандартом при описании моделей и процессов на различных уровнях детализации.

Алгоритм структурно-параметрического синтеза системы управления документооборотом представлен в виде функциональной схемы в нотации IDEF0 (рисунок 1), которая включает в себя определенные процессы [14]:

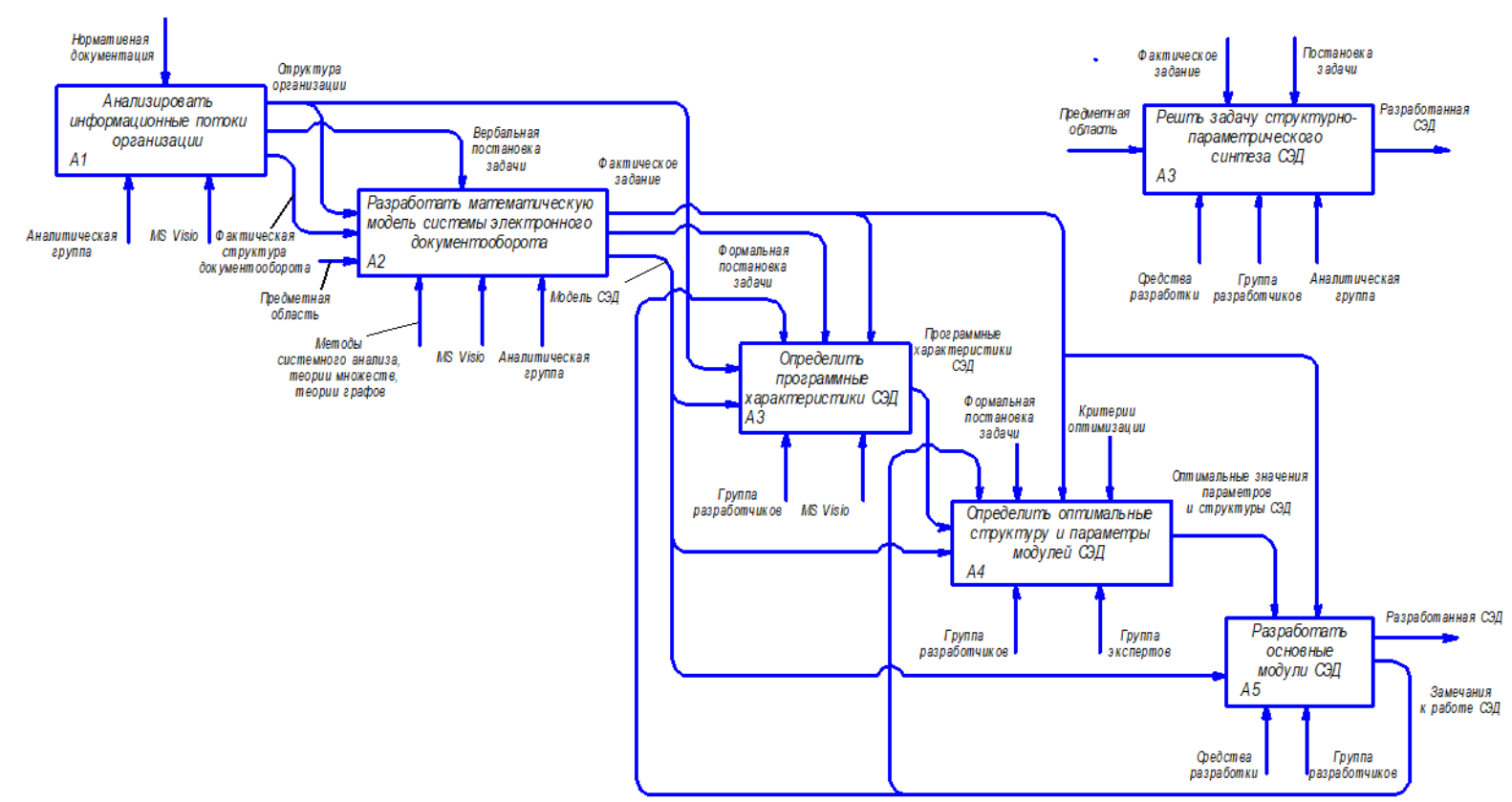

Рисунок 1. Алгоритма структурно-параметрического синтеза.

А1. Разбор данных поступающей информации, используемой в организации. Входной информацией для первого пункта алгоритма является информация о тематической области организации. На первом шаге, данных поступающей информации, используемой в 
организации, изучаются и регистрируются в неформализованной форме с использованием различных вербальных или графических блок-схем, например, с использованием инструментов Microsoft Visio, LucidChart, ASCIIFlow Infinity, Gliffy и др. Затем рассматривается архитектура организации, чтобы составить схему подразделений с перечнем задач и необходимых документов, подлежащих обработке, соответствующих каждому отделу или службе. На следующем шаге составляется набор ожиданий в отношении архитектуры документооборота и окончательной реализации системы управления на основе заявленных требований управленческой команды организации, с учетом устно поставленных задач.

А2. Создание математической модели системы управления документами. На основе анализа моделирования электронного документооборота и имеющихся систем документооборота с использованием подходов системного анализа и математического моделирования создана математическая модель управления, учитывающая архитектуру документооборота организации, программные и аппаратные характеристики системы, оценки ее экономических затрат, продуктивность и качество работы, области определения переменных, уравнения, описывающие процессы, протекающие в документообороте. На основе этой модели и теории графов была разработана классификация основных структур информационных потоков, которая позволяет осуществлять формализацию и программную реализацию в процессах оптимальног движения документов.

А3. Определение программных характеристик системы документооборота. Данный этап непосредственно создает архитектуру системы управления и особенности ее использования (скорость, отказоустойчивость, качество, соответствие пользователей и т.д.), поскольку они определяются характеристиками программного обеспечения - используемыми инструментами разработки, структурой модулей и окончательной реализацией программного обеспечения. На основе поставленных перед системой технических условий и формальной постановки задачи структурно-параметрического синтеза формируется перечень условий к информационной системе, после чего осуществляется подбор средств создания и архитектуры модулей, которая включает функции каждого модуля, включает библиотеки кода и общие формы интерфейса. Данные компоненты полностью определяют программные характеристики создаваемой системы управления. Когда система обновляется и оптимизируется, алгоритм получает управляющие входные данные в виде набора комментариев от пользователей или руководящего персонала организации, после чего программные характеристики системы управления пересматриваются.

А4. Определение оптимальных структур и параметров модулей системы управления. На первом шаге итерации структурно-параметрического синтеза системы управления документами задается начальное состояние параметров, после чего проверяются ограничения 
задачи и вычисляется значение критерия. Если полученный результат является оптимальным, соответствует всем ограничениям и требованиям управляющего воздействия, то значения параметров передаются для программной реализации системы управления, в противном случае значения параметров изменяются, предыдущие шаги повторяются до тех пор, пока не будет подобран оптимальный набор параметров, при котором целевая функция достигает своего экстремума.

А5. Разработка основных модулей системы управления документооборотом. На основе полученной математической модели системы управления, оптимальных значений параметров и структуры СЭД разрабатываются модули системы управления для исполнительнораспорядительного блока. Для этого используется типовая схема разработки модулей. Она состоит из следующих этапов: создание базы данных для модуля; разработка интерфейса модуля с использованием выбранных инструментов; реализация основных функций модуля, в том числе с привлечением сторонних библиотек программного кода; реализация разграничения доступа к информации по оптимальной модели; реализация средств поиска информации в модуле; наполнение базы данных необходимой информацией. Следуя данной последовательности этапов, разрабатывается типовой модуль системы управления, отвечающий требованиям к его функциональности и программной реализации.

После завершения разработки производится отладка и тестирование модулей, выявляются ошибки, замечания по работе или предложения поступают на вход блока А3 в виде управляющего воздействия, и начинается новая итерация структурно-параметрического синтеза системы управления документооборотом.

\section{3. Заключение}

Реализация алгоритма структурно-параметрического синтеза разрешает уменьшить временную и количественную составляющую проведенных работ за счет использования модульной системы проектирования и формализации объектов документооборота, процессов их перемещения и взаимодействия. Применяя параметры, рассматриваемые в алгоритме в виде математической модели системы управления, систематизации структур информационных данных, условий раздельного подхода, постановки задачи улучшения программно-аппаратных характеристик системы управления, можно значительно упростить процесс представления документооборота, создание и совершенствование системы, а также обеспечить ее конкурентоспособность за счет увеличения ее результативности.

\section{Благодарности}

Работа выполнена в рамках государственного задания Минобрнауки России по теме «Концептуальное моделирование информационно-образовательной среды воспроизводства 
человеческого капитала в условиях цифровой экономики» № 121102600069-2. Работа выполнена в рамках государственного задания Минобрнауки России по теме «Разработка новых методов автономной навигации космических аппаратов в космическом пространстве» 121102600068-5.

\section{Список литературы}

[1] Емалетдинова, Л.Ю. Нейронечеткая модель аппроксимации сложных объектов с дискретным выходом / Л.Ю. Емалетдинова, А.С. Катасев, А.П. Кирпичников // Вестник Казанского технологического университета. - 2014. - № 17(5). - С. 295-299.

[2] Емалетдинова, Л.Ю. Моделирование диагностической деятельности на основе нечеткой нейронной сети / Л.Ю. Емалетдинова, Д.Ю. Стрункин // Искусственный интеллект и принятие решений. - 2010. - № 3. - С. 73-78.

[3] Карцан, И.Н. Оптимизация системы управления на базе процедуры TOPSIS. B книге: Технологии получения и обработки информации о динамических объектах и системах / И.Н. Карцан, С.В. Ефремова, Д.С. Горовой // сборник тезисов Всероссийской научно-практической конференции. - 2020. - С. 178-186.

[4] Карцан, И.Н. Агрегативно-декомпозиционный подход при построении сложных систем управления. В книге: Технологии получения и обработки информации о динамических объектах и системах / И.Н. Карцан, С.В. Ефремова, К.А. Иванов // сборник тезисов Всероссийской научно-практической конференции. - 2020. - С. 187 194.

[5] Емельяненко, А.Р. Использование аппарата экспертных систем в процессе поддержки принятия решений / А.Р. Емельяненко, Д.Д. Лапшин, Г.А. Квашнина // Вестник Воронежского государственного технического университета. - 2009. - № 5(5). - С. 244-249.

[6] Белокуров, С.В. Задача оптимального распределения временного резерва для оптимизации антивирусной защиты в инфокоммуникационных системах УИС / С.В. Белокуров, Д.Г. Зыбин, Н.В. Рощин, А.А. Змеев // Актуальные проблемы деятельности подразделений УИС. - 2013. - С. 35-39.

[7] Карцан, И.Н. Применение оптимизационно-имитационной модели при построении структуры управления. В книге: Технологии получения и обработки информации о динамических объектах и системах / И.Н. Карцан, С.В. Ефремова, К.А. Иванов // сборник тезисов Всероссийской научно-практической конференции. - 2020. - С. 195 202.

[8] Карцан, И.Н. Оптимизация отказоустойчивого программного обеспечения. В сборнике: 
Вопросы контроля хозяйственной деятельности и финансового аудита, национальной безопасности, системного анализа и управления / И.Н. Карцан, В.О. Скрипачев // Сборник материалов V Всероссийской научно-практической конференции. - 2020. 337-341.

[9] Карцан, П.И. Применение неалгоритмических моделей оценки стоимости программного обеспечения. / П.И. Карцан, И.Н. Карцан // В сборнике: Решетневские чтения. Материалы XXIV Международной научно-практической конференции, посвященной памяти генерального конструктора ракетно-космических систем академика М. Ф. Решетнева. - 2020. - С. 651-653.

[10] Калач А.В. Особенности применения систем поддержки принятия решений при ликвидации последствии чрезвычайных обстоятельств / А.В. Калач, Д.Г. Зыбин, С.А. Бокадаров // Вестник Воронежского института ФСИН России. - 2020. - № 3. - С. 60-66.

[11] Калач, А.В. Поддержка принятия решений при управлении спасательными формированиями / А.В Калач., Д.Г. Зыбин, Е.З. Арифуллин. - Воронеж: Воронежский институт ФСИН России, 2019. - 160 с.

[12] Efremova, S.V. An ordered ranking multi-attributive model for decision-making systems with attributes of control systems software / S.V. Efremova, I.N. Kartsan, A.O. Zhukov // IOP Conference Series: Materials Science and Engineering. - 2021. - № 1047(1) 012068. DOI: 10.1088/1757-899X/1047/1/012068.

[13] Saramud, M.V. Development of methods for equivalent transformation of gert networks for application in multi-version software / M.V. Saramud, P.V. Zelenkov, I.V. Kovalev, D.I. Kovalev, I.N. Kartsan // IOP Conference Series: Materials Science and Engineering. 2016. - № 155(1) 012015. DOI: 10.1088/1757-899X/155/1/012015.

[14] Обухов, А.Д. Алгоритм структурно-параметрического синтеза системы электронного документооборота научно-образовательного учреждения // Вопросы современной науки и практики. Университет им. В. И. Вернадского. - 2016. - 1(59). - С. 199-209. DOI: 10.17277/voprosy.2016.01.pp.199-209. 